\title{
Trends of Pediatric Outpatients Prescribing in Umm Al Quwain, United Arab Emirates
}

\author{
Suleiman I. Sharif*, Aseel H. Nassar, Fatima K. Al-Hamami, Maha M. Hassanein, \\ Ashkur H. Elmi, Rubian S. Sharif \\ Department of Pharmacy Practice \& Pharmacotherapeutics, College of Pharmacy, University of Sharjah, \\ Sharjah, United Arab Emirates \\ Email: sharifsi@sharjah.ac.ae
}

Received 17 December 2014; accepted 3 January 2015; published 14 January 2015

Copyright (C) 2015 by authors and Scientific Research Publishing Inc.

This work is licensed under the Creative Commons Attribution International License (CC BY). http://creativecommons.org/licenses/by/4.0/

(c) (i) 0pen Access

\section{Abstract}

Background: Data with regard to local drug prescribing in pediatric population is scarce. This study was carried out to investigate the patterns of drug prescribing for pediatric outpatient in a general hospital in the United Arab Emirates. Methods: A total of 707 prescriptions were collected from a governmental hospital in Umm Al Quwain, United Arab Emirates covering the months of June and July, 2014. Encounters issued for patients older than 12 years were rejected. A total of 520 prescriptions for age groups ranging from 1 week to 12 years were studied. Prescriptions were analyzed using WHO drug use indicators. Results: All prescriptions were electronic and head lettered by the name of the hospital. Average number of drugs per prescriptions was 2.6 and all drugs were generics. Name of patient, age and gender and prescriber's name and E-signature were present in $100 \%$. Patient's address, allergy and diagnosis were present in $21.15 \%, 83.26 \%$ and $64.42 \%$ of prescriptions respectively. Complete dosage regimen was present in all encounters. Pa-

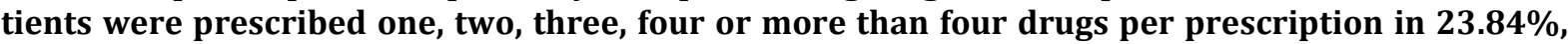
$27.88 \%, 26.53 \%, 12.69 \%$, and $8.65 \%$ respectively. The most commonly prescribed therapeutic classes of drugs were antibiotics $(44.60 \%)$, antihistamines $(43.65 \%)$, and analgesics/antipyretics $(32.30 \%)$. The most commonly prescribed drugs among each class were amoxicillin $(40 \%)$, xylometazoline $(61.23 \%)$, and paracetamol $(87.5 \%)$. Conclusion: Present results indicate that prescribing trends for pediatric population seems to be rational. However, there is over use of antibiotics and there are some areas that warrant further attention by the prescribers for a more significantly rational prescribing.

\section{Keywords}

Prescriptions, Trends, Pediatrics, Outpatients, Drug Use Indicators

\footnotetext{
${ }^{*}$ Corresponding author.
}

How to cite this paper: Sharif, S.I., Nassar, A.H., Al-Hamami, F.K., Hassanein, M.M., Elmi, A.H. and Sharif, R.S. (2015) Trends of Pediatric Outpatients Prescribing in Umm Al Quwain, United Arab Emirates. Pharmacology \& Pharmacy, 6, 9-16. 


\section{Introduction}

Irrational drug use increases the cost of treatment, incidence of adverse drug reactions and hospitalization. On the other hand, rational prescribing can be evaluated through prescription analysis to study the patterns of prescribing among physicians. Periodical evaluation of trends of prescribing is essential to point out areas for improvement and increase the awareness of prescribers to possible errors in their daily practice. In studying prescribing patterns, focus is mainly on errors which may be in the form of incomplete prescription or incorrect content [1]. It has been suggested that as community pharmacists have no access to patient's information, their use of scientific knowledge is not possible in cases of prescriptions with errors or incomplete information [2]. On the other hand, the situation in hospital practice is different. However, it is still possible to demonstrate encounters with errors or incomplete information.

The World Health Organization (WHO) [3] has formulated a set of core drug use indicators (Table 1), which measure the performance of prescribers, patients experience at health facilities and whether the health personnel can function effectively. The assessment of drug use indicators according to WHO guidelines on how to investigate drug use in health facilities is prescribing indicators, patient care indicators, facility indicators and complementary indicators [4].

Studies that investigated the prescribing trends in adults [5]-[20] are far in excess of those in pediatric patients [21]-[28]. It has been pointed out that drugs marketed for adult use, may possibly, be used in an off-label manner in children [2]. It has been shown that $80 \%$ - 93\% of medications used in European and Australian neonatal wards are off-label or unlicensed [29].

Moreover, harmful medication errors are three times more common in pediatric than adult patients [30]. It must be remembered that most of the drugs prescribed for children have not been tested in the pediatric population due to the difficulties in carrying out clinical studies in children and ethical issues due to children not being able to make their own decisions to participate in a clinical trial. Therefore, many medications have not been approved by the Food and Drug Administration for children [31]. An essential component in rational drug prescribing is the availability of an approved guideline such as a list of essential drugs. For prescribing for children, the first guideline was issued by the WHO in October, 2007 [32].

Children are among the most vulnerable groups to possible harmful adverse effects of drugs and studies on drug use in children in UAE are lacking. The present study was undertaken to evaluate patterns of prescribing in paediatric population.

\section{Table 1. Core drug use indicators in pediatric outpatients of a general hospital.}

Prescribing indicators

Average number of drugs per encounter.

Percentage of drugs prescribed by generic name.

Percentage of antibiotics prescribed.

Percentage of injections prescribed.

Percentage of drugs prescribed from essential

drug list or formulary.

Patient care indicators

Average consultation time.

Average dispensing time.

Percentage of drugs actually dispensed.

Percentage of drugs adequately labeled.

Patient's knowledge of correct dosage.

Facility indicators

Availability of essential drugs list or formulary.

Availability of key drugs.
2.6

$100 \%$

$44.6 \%$

$0.38 \%$

$100 \%$
20 Minutes

12 Minutes

$98 \%$

$100 \%$

Not assessed

$\mathrm{BNF}$

85\% 


\section{Methods}

A hospital base cross sectional study was carried out on prescriptions issued to pediatric outpatients. The study was approved by the Ethics Committee of the Medical Campus of the University of Sharjah and hospital approval was obtained prior to collecting prescriptions. A total of 707 prescriptions were collected from a governmental general hospital in the Emirate of Umm Al Quwain, United Arab Emirates. All prescription were issued during the months of June and July, 2014. All collected encounters were electronic prescriptions issued to outpatient aged one week to 19 years. A total of 187 prescriptions issued to patients older than 12 years of age were rejected and not included in the study. The rest (520) of prescription were subjected to the study. These prescriptions were subjected to analysis according to WHO core indicators for drug use in health facilities [3]. Indicators (Table 1) addressed include prescribing indicators such as average number of drugs per encounter, \% of drugs prescribed by generic name, \% of encounters with an antibiotic prescribed, \% of encounters with an injection prescribed and \% of drugs prescribed from essential drugs list or formulary. Under patient care indicators, we determined average consultation and dispensing times, \% of drugs actually dispensed and those adequately labeled. For facility indicators, availability of key drugs and a copy of essential drugs list or formulary were determined. Collected prescriptions were also analyzed for the presence of information with regard to prescriber, patient and prescribed drugs. These include patient's name, age, sex, and address, and the physician's name, address, signature, and license number. The number of drugs per prescription, dosage, frequency of administration, duration of treatment, duplicate drugs of the same therapeutic class, possible drug-drug interactions and whether prescription is clear and illegible were also considered. We also studied the most commonly prescribed therapeutic classes and the most frequently prescribed drug of each common class were counted. Documentation of history of allergy and brief diagnosis of the condition were observed. We also determined the \% of prescriptions with increasing number of drugs and the most common pathological conditions for which drugs were prescribed

\section{Results}

\subsection{Prescribing Indicators}

As shown in Table 1 the number of prescriptions studied was 520 with a total number of 1,336 drugs prescribed and an average number of 2.6 drugs per prescription. The percentages of encounters with an antibiotic and those with an injection were $44.6 \%$ and $0.38 \%$ respectively. All prescribed drugs were from a formulary namely embedded in the electronic prescribing system used in the hospital.

\subsection{Patient Care Indicators}

Average consultation and dispensing times were 20 and 12 minutes respectively. All prescribed drugs were adequately labeled using the electronic system, and almost all (98\%) of the prescribed drugs were actually dispensed. Parent's knowledge of correct dosage was not assessed in the present study (Table 1).

\subsection{Facility Indicators}

The electronic system of the hospital relies on an electronic drug formulary. In addition, the British National Formulary (BNF) was also available (Table 1).

Patients were distributed into males (56.34\%) and females (43.65\%). The majority (53.46\%) of patients were 13 months - 6 years of age. Neonates comprised (1.15\%), infants (5 weeks - 1 year, 13.65\%) and the rest (31.73\%) were 6 - 12 years of age (Table 2).

All prescriptions were electronic and were head lettered by the name of the hospital. As shown in Table 3 , patient's name, age and gender were present in $100 \%$ of the prescriptions. Patients address, history of allergy and brief diagnosis of the condition were present in $21.15 \%, 83.26 \%$ and $64.42 \%$ of the prescriptions respectively. Regarding the prescriber information, the name was present in $100 \%$ of the prescriptions while signature of the prescriber was an electronic one.

Table 3, also shows that the dose, route of administration, frequency of administration and the duration of treatment were present in all prescriptions. All drugs were prescribed by generic name. As shown in Table 4, patients were prescribed one, two, three, four or more than four drugs per prescription in $24 \%, 28 \%, 26.53 \%$, $12.69 \%$ and $8.65 \%$ respectively. 
Table 2. Distribution of pediatric outpatients according to age and gender.

\begin{tabular}{ccc}
\hline & Parameter & Number of patients (\%) (n= 520) \\
\cline { 2 - 3 } & Neonates (up to 4 weeks) & $6(1.15 \%)$ \\
Age & Infants ( 5 weeks - 1 year) & $71(13.65 \%)$ \\
& Children (13 months - 6 years) & $278(53.46 \%)$ \\
& Children (7 - 12 years) & $165(31.73 \%)$ \\
\hline \multirow{2}{*}{ Sex } & Females & $227(43.65 \%)$ \\
& Males & $293(56.34 \%)$
\end{tabular}

Table 3. Percentages of prescriptions containing prescriber's, patient's and prescribed drug's information.

\begin{tabular}{ccc}
\hline & Information & $\mathbf{\%}(\mathbf{n}=\mathbf{5 2 0})$ \\
\hline Prescriber's & Name & $100 \%$ \\
& Address & $100 \%$ \\
& Signature & E-signature \\
\hline \multirow{2}{*}{ Patient's } & Name & $100 \%$ \\
& Address & $100 \%$ \\
& Gender & $100 \%$ \\
& Address & $21.15 \%$ \\
& Allergy & $83.26 \%$ \\
& Diagnosis & $64.42 \%$ \\
\hline & Dose & $100 \%$ \\
& Route of administration & $100 \%$ \\
\hline
\end{tabular}

Table 4. Number of drugs per prescription.

\begin{tabular}{cc}
\hline Number of drugs/prescription & Number (\%) of prescriptions (n= 520) \\
\hline One drug & $125(24 \%)$ \\
Two drugs & $146(28 \%)$ \\
Three drugs & $138(26.53 \%)$ \\
Four drugs & $66(12.69 \%)$ \\
More than four drugs & $45(8.65 \%)$ \\
\hline
\end{tabular}

Antibiotics were the most commonly (44.6\%) prescribed drugs with amoxicillin being the most frequently (40\%) given drug. Second in ranking were antihistmaines (43.65\%) with xylometazoline (61.23\%) and third are the analgesic/antipyretic drugs (32.30\%) with paracetamol (87.5\%) as number one of this class (Table 5). The most frequent diagnosis encountered were in the order of; dermatological disorders, tonsillitis, rhinitis, otitis media, gastroenteritis, upper respiratory tract infection, bronchial asthma, acute bronchitis, fever, iron deficiency anemia, mouth ulceration, urinary tract infection, conjunctivitis, cerebral palsy, cough, enuresis, cerumen impaction, and seizures (Table 6).

\section{Discussion}

Several tools have been introduced to evaluate the quality of prescribing. The aim of this study was to determine 
Table 5. Most commonly prescribed therapeutic classes and drugs of each class.

\begin{tabular}{ccc}
\hline \multicolumn{1}{|c}{ Therapeutic class } & Drug (s) (n= 520) & Number (\%) \\
\hline Antibiotics 232(44.6\%) & Amoxicillin & $93(40.0 \%)$ \\
& Cefuroxime axetil & $54(23.3 \%)$ \\
& Fusidic acid & $48(20.7 \%)$ \\
Antihistamines 227 (43.7\%) & Xylometazoline & $139(61.2 \%)$ \\
& Cetirizine HCl & $104(45.8 \%)$ \\
Analgesics/antipyretics 168(32.3\%) & Loratidine & $57(25.1 \%)$ \\
& Paracetamol & $147(87.5 \%)$ \\
\hline
\end{tabular}

Table 6. Number and percentage of diagnosed conditions for which drugs were prescribed.

\begin{tabular}{cc}
\hline Condition & Number of cases (\%) (n = 520) \\
\hline Dermatological disorders & $30(5.77 \%)$ \\
Tonsillitis & $23(4.42 \%)$ \\
Rhinitis & $16(3.08 \%)$ \\
Otitis media & $14(2.69 \%)$ \\
Gastroentiritis & $13(2.50 \%)$ \\
Upper respiratory tract infection & $10(1.92 \%)$ \\
Bronchial asthma & $6(1.15 \%)$ \\
Acute bronchitis & $5(0.96 \%)$ \\
Fever & $5(0.96 \%)$ \\
Iron deficiency anaemia & $4(0.77 \%)$ \\
Mouth ulceration & $3(0.58 \%)$ \\
Urinary tract infection & $3(0.58 \%)$ \\
Conjunctivitis & $2(0.38 \%)$ \\
Cerebral palsy & $2(0.38 \%)$ \\
Cough & $2(0.38 \%)$ \\
Enuresis & $2(0.38 \%)$ \\
Cerumen impaction Seizures & $2(0.38 \%)$ \\
Seizures & $1(0.19 \%)$ \\
\hline
\end{tabular}

the quality of prescribing in paediatric outpatients in a general hospital in one of the Emirates of United Arab Emirates using the WHO core indicators for drug use. In the present study, the average number of drugs per encounter was 2.6. This is higher than the recommended figure of 2, however, it is similar to 2.5 in India [2], more than that in Ethiopia [21] but less than that in KSA [22]. Prescribing large number of drugs to a child increases the risk of adverse effects, drug interactions, dispensing errors and leads to less understanding of parents of dosages regimens [23] [26]. It has been suggested that the optimal indicator values for the average number of drugs per encounter, and prescribing antibiotics and injections largely depend on disease patterns, policies and treatment guidelines and therefore may vary from country to country and over time [33].

Our results indicate that there is a tendency for polypharmacy as almost $47.87 \%$ of prescriptions contain three drugs and more. However, since all prescriptions were electronic, the possible risks of interaction is reduced as 
the electronic system reminds the prescriber of such possible interactions. Again the electronic system must have had an influence on prescribing as in all encounters only generic drugs were prescribed. Increasing generic prescribing would rationalize the use and reduce the cost of drugs [34]. It has been reported that usually poor generic prescribing is due to non-availability of the pediatric formulations in the hospital pharmacy [27] [35]. In the present study, almost all (98\%) of the prescribed drugs were dispensed.

Drug doses, dosing interval, and duration of dosing were present in all encounters. Selection of drugs to be prescribed from an electronic drug database verifies prescriptions and ensures the consideration of all drug related parameters, such as dose, route, and duration of treatment [5].

In the present study, the information on patient's name, age, and gender were present in all encounters. However, address of patient was missing from about $80 \%$ of prescriptions. This may not be a problem if the prescriber or pharmacist need to correct an error of prescribing or dispensing or to follow up with the patient because the hospital have the address of the patient in his file. Not mentioning the patient's address constitutes a problem only if the patient has to seek medications outside the hospital and a dispensing error need to be corrected by the community pharmacist who dispensed the medication.

Allergy was not documented in $17 \%$ of the prescriptions. This is important particularly in paediatric population and when one consider the high \% of encounters (44.6\%) with antibiotics. Such use of antibiotics is similar to $43.19 \%$ in India [36], much higher than (21\%) reported for Omani pediatric population [37] and less than (53.42\%) reported in Ethiopia [21]. It is a fact that antibiotics are routinely used for the treatment of pediatric illnesses and still irrationally used for inappropriate indications such as upper respiratory tract infections, acute otitis media and acute gastroenteritis. These three condition were among the most frequently diagnosed in the present study. The irrational use of antibiotics calls for more efforts and effective interventions to promote rational antibiotic use particularly in pediatric population. It is important to stress on the importance of continuous monitoring of drug use in pediatrics as part of evaluation of risk/benefit of therapeutics in children [38].

Results of our study indicate that about one third of encounters did not mention the diagnosis. A brief diagnosis of the condition is also helpful to the pharmacist to ensure that the drugs prescribed are appropriate for the patient's condition [5] and also can be helpful to the pharmacist in correcting, in consultation with the prescriber, any possible medication error. With regard to the prescriber's information, all encounters were letter headed in the name and address of hospital, name of prescriber was mentioned and each encounter carried an electronic signature of the prescriber.

The most commonly prescribed therapeutic class was antibiotics These were encountered in (44.6\%) of all prescriptions studied, and amoxicillin (40.0\%) was the most commonly prescribed of this class. Antihistamines were the second most commonly (43.65\%) prescribed class and xylometazoline (61.23\%) was the most common antihistamine used. Third on the list were analgesic antipyretic drugs (32.30\%) with paracetamol (87.5\%) being the most common drug of the class. Studies from Sweden, the Netherlands, and Denmark showed that anti-infective drugs, respiratory drugs, and dermatological drugs were the most commonly prescribed drugs in pediatric patients [39]-[41]. On the other hand, the most frequently diagnosed conditions were; dermatological disorders, tonsillitis, rhinitis, otitis media, gastroenteritis, upper respiratory tract infection, bronchial asthma, acute bronchitis, fever, iron deficiency anemia. This may have bearing on the most commonly prescribed drug classes.

\section{Conclusion}

In conclusion, the present study provides baseline data useful for comparison with results of future local pediatric drug utilization studies. Results of the present study indicate that there is, in general, a trend for rational prescribing practice in pediatrics ward of the hospital, especially with regard to information concerning prescriber, patient and prescribed drugs. Attention must be made to document the diagnosed condition and history of allergy. Irrational use of antibiotic for inappropriate indications such as upper respiratory tract infections and acute Otitis media should be discouraged through proper and effective interventions. This could be achieved by stressing on rational drug use, evidence-based medicine and the hazards of irrational antibiotic use in medical curriculum, and continuing medical education and healthcare professional development programs.

\section{Acknowledgements}

We are grateful to the administration of Umm Al Qwuain Hospital and Umm Al Qwuain Medical District for 
their kind cooperation during data collection process.

\section{References}

[1] Rupp, M.T., Schondelmeyer, S.W., Wilson, G.T. and Krause, J.E. (1988) Documenting Prescribing Errors and Pharmacist Interventions in Community Pharmacy Practice. American Pharmacy, 28, 30-37.

[2] Pandey, A.A., Prakash, S.B. and Bhatkule, R. (2010) Prescription Analysis of Pediatric Outpatient Practice in Nagpur City. Indian Journal of Community Medicine, 35, 70-73. http://dx.doi.org/10.4103/0970-0218.62564

[3] World Health Organization (1993) How to Investigate Drug Use in Health Facilities: Selected Drug Use Indicators. WHO/DAP/93.1. World Health Organization, Geneva, 1-87.

[4] Akhtar, M.S., Divya, V., Pillai, K., Kiran, D., Roy, M.S., Najmi, A.K., et al. (2012) Drug Prescribing Practices in Paediatric Department of a North Indian University Teaching Hospital. Asian Journal of Pharmaceutical and Clinical Research, 5, 146-149.

[5] Sharif, S.I., AlShaqra, M., Hajar, H., Shamout, A. and Weis, L. (2008) Patterns of Drug Prescribing in a Hospital in Dubai-UAE. Libyan Journal of Medicine, 3, 10-12.

[6] Sharif, S.I., Alabdouli, A.H. and Sharif, R.S. (2013) Drug Prescribing Trends in a General Hospital in Sharjah, United Arab Emirates. American. Journal of Pharmacological Sciences, 1, 6-9.

[7] Guyon, A.B., Barman, A., Ahrned, J.U., Ahmed, A.U. and Alam, M.S. (1994) A Baseline Survey on Use of Drugs at the Primary Health Care Level in Bangladesh. Bull WHO, 72, 265-271.

[8] Krause, G., Borchert, M., Benzler, J., et al. (1999) Rationality of Drug Prescriptions in Rural Health Centres in Burkina Faso. Health Policy and Planning, 14, 291-298. http://dx.doi.org/10.1093/heapol/14.3.291

[9] Chareonkul, C., Khun, V.L. and Boonshuyar, C. (2002) Rational Drug Use in Cambodia: Study of Three Pilot Health Centers in Kampong Thorn Province. Southeast Asian Journal of Tropical Medicine and Public Health, 33, 418-424.

[10] Desta, Z., Abula, T., Beyene, L., Fantahun, M., Yohannes, A.G. and Ayalew, S. (1997) Assessment of Rational Drug Use and Prescribing in Primary Health Care Facilities in North West Ethiopia. East African Medical Journal, 74, 758763.

[11] Bosu, W.K. and Ofori-Adjei, D. (2000) An Audit of Prescribing Practices in Health Care Facilities of the Wassa West District of Ghana. West African Journal of Medicine, 19, 298-303.

[12] Hamadeh, G.N., Dickerson, L.M., Saab, B.R. and Major, S.C. (2001) Common Prescriptions in Ambulatory Care in Lebanon. Annals of Pharmacotherapy, 35, 636-640. http://dx.doi.org/10.1345/aph.10175

[13] Simon, N., Hakkou, F., Minani, M., Jasson, M. and Diquet, B. (1998) Drug Prescription and Utilization in Morocco. Therapie, 53, 113-120.

[14] Ravi Shankar, P., Partha, P. and Nagesh, S. (2002) Prescribing Patterns in Medical Outpatients. International Journal of Clinical Practice, 56, 549-551.

[15] Chukwuani, C.M., Onifade, M. and Sumonu, K. (2002) Survey of Drug Use Practices and Antibiotic Prescribing Pattern at a General Hospital in Nigeria. Pharmacy World and Science, 24, 188-195. http://dx.doi.org/10.1023/A:1020570930844

[16] Najmi, M.H., Hafiz, R.A., Khan, I. and Fazli, F.R. (1998) Prescribing Practices: An Overview of Three Teaching Hospitals in Pakistan. Journal of Pakistan Medical Association, 48, 73-77.

[17] Massele, A.Y., Nsimba, S.E. and Rimoy, G. (2001) Prescribing Habits in Church-Owned Primary Health Care Facilities in Dar Es Salaam and Other Tanzanian Coast Regions. East African Medical Journal, 78, 510-514. http://dx.doi.org/10.4314/eamj.v78i10.8958

[18] Trap, B., Hansen, E.H. and Hogerzeil, H.V. (2002) Prescription Habits of Dispensing and Non-Dispensing Doctors in Zimbabwe. Health Policy and Planning, 17, 288-295. http://dx.doi.org/10.1093/heapol/17.3.288

[19] Biswas, N.R., Biswas, R.S., Pal, P.S., et al. (2000) Patterns of Prescriptions and Drug Use in Two Tertiary Hospitals in Delhi. Indian Journal of Physiology and Pharmacology, 44, 109-112.

[20] Rehan, H.S. and Lal, P. (2002) Drug Prescribing Pattern of Interns at a Government Healthcare Centre in Northern India. Tropical Doctor, 32, 4-7.

[21] Bergicho, M., Mohammed, M.A. and Wabe, N.T. (2012) Assessment of the Pattern of Drug Prescribing in Pediatrics Ward in Tertiary Setting Hospital in Addis Ababa, Ethiopia. Gaziantep Medical Journal, 18, 61-65.

[22] Gupta, N., Safhi, M.M., Sumaily, J.M.Y. and Agarwal, M. (2013) Drug Prescribing Patterns in Children Registered in the Department of Pediatrics of Jizan General Hospital of Jizan, KSA. International Journal of Pharmacy and Pharmaceutical Sciences, 5, 397-399. 
[23] Karande, S., Sankhe, P. and Kulkarni, M. (2005) Patterns of Prescription and Drug Dispensing. The Indian Journal of Pediatrics, 72, 117-121. http://dx.doi.org/10.1007/BF02760693

[24] Ghaleb, M.A. and Wong, I.C. (2006) Medication Errors in Paediatric Patients. Archives of Disease in ChildhoodEducation and Practice, 91, 20. http://dx.doi.org/10.1136/adc.2005.073379

[25] Thiruthopu, N.S., Mateti, U.V., Bairi, R., Sivva, D. and Martha, S. (2014) Drug Utilization Pattern in South Indian Pediatric Population: A Prospective Study. Perspectives in Clinical Research, 5, 178-183. http://dx.doi.org/10.4103/2229-3485.140558

[26] Dinesh, K.G., Padmasani, L., Vasantha, J., Veera, R.B., Sudhakar, P. and Uma, M.R. (2011) Drug Prescribing Pattern among Pediatricians in an Out-Patient Department of Tertiary Care Teaching Hospital. Indian Journal of Pharmacy Practice, 4, 64-68.

[27] Nazima, Y.M., Sagun, D. and Barna, G. (2009) Prescribing Pattern in a Pediatric Out-Patient Department in Gujarat. Bangladesh Journal of Pharmacology, 4, 39-42.

[28] Shamshy, K., Mufidabegum, I. and Perumal, P. (2011) Drug Utilization of Antimicrobial Drug in Pediatrics Population in a Tertiary Care Hospital in Erode, Tamilnadu, India. International Journal of PharmTech Research, 3, 1530-1536.

[29] Lindell-Osuagwu, L., Korhonen, M.J., Saano, S., Helin-Tanninen, M., Naaranlahti, T. and Kokki, H. (2009) Off-Label and Unlicensed Drug Prescribing in Three Pediatric Wards in Finland and Review of the International Literature. Journal of Clinical Pharmacology \& Therapeutics, 34, 277-287. http://dx.doi.org/10.1111/j.1365-2710.2008.01005.x

[30] Kaushal, R., Bates, D.W., Landrigan, C., McKenna, K.J., Clapp, M.D., Federico, F. and Goldmann, D.A. (2001) Medication Errors and Adverse Drug Events in Pediatric Inpatients. The Journal of the American Medical Association, 285, 2114-2120. http://dx.doi.org/10.1001/jama.285.16.2114

[31] You, M.L., Chun, Y., Yung, T.K., Man, Y.H. and Hsiang, Y.C. (2010) Outcomes of Pharmacy Interventions on Pediatric Medication Prescribing Patterns in Taiwan. International Journal of Clinical and Experimental Medicine, 2, $173-$ 180. http://dx.doi.org/10.1016/S1878-3317(10)60027-7

[32] WHO (2007) WHO Model List of Essential Medicines for Children. First List. http://www.who.int/medicines/publications/essentialmedicines/en/index.html

[33] Mahmoud, R.K., Kheder, S.I. and Ali, H.M. (2014) Prescribing Rationality in Khartoum State, Sudan: An update. Sudan Medical Monitor, 9, 61-66. http://dx.doi.org/10.4103/1858-5000.146575

[34] Quick, J.D., Hogerzeil, H.V., Velasquez, G. and Rago, L. (2002) Twenty-Five Years of Essential Medicines. Bulletin of the World Health Organization, 80, 913-914.

[35] Pramil, T., Rajiv, A. and Gaurav, G. (2012) Pattern of Prescribing at a Pediatric Outpatient Setting in Northern India. Indian Journal of Pharmacy Practice, 5, 40-44.

[36] Ashraf, H., Handa, S. and Khan, N.A. (2010) Prescribing Pattern of Drugs in Outpatient Department of Child Care Centre in Moradabad City. International Journal of Pharmaceutical Sciences Review and Research, 3, Article 001.

[37] Al-Balushi, K.A., Al-Ghafri, F., Al-Zakwani, I. and Al-Sawafi, F. (2013) Drug Utilization Pattern in an Omani Pediatric Population. Journal of Basic and Clinical Pharmacy, 4, 68-72.

[38] Chai, G., Governale, L., McMahon, A.W., Trinidad, J.P., Staffa, J. and Murphy, D. (2012) Trends of Outpatient Prescription Drug Utilization in US Children, 2002-2010. Pediatrics, 130, 23-31.

[39] Madsen, H., Andersen, M. and Hallas, J. (2001) Drug Prescribing among Danish Children: A Population-Based Study. European Journal of Clinical Pharmacology, 57, 159-165. http://dx.doi.org/10.1007/s002280100279

[40] Schirm, E., Tobi, H. and de Jong-van den Berg, L.T. (2002) Unlicensed and off Label Drug Use by Children in the Community: Cross Sectional Study. British Medical Journal, 324, 1312-1313. http://dx.doi.org/10.1136/bmj.324.7349.1312

[41] Silwer, L. and Lundborg, C.S. (2005) Patterns of Drug Use during a 15 Year Period: Data from a Swedish County, 1988-2002. Pharmacoepidemiology and Drug Safety, 14, 813-820. http://dx.doi.org/10.1002/pds.1124 
Scientific Research Publishing (SCIRP) is one of the largest Open Access journal publishers. It is currently publishing more than 200 open access, online, peer-reviewed journals covering a wide range of academic disciplines. SCIRP serves the worldwide academic communities and contributes to the progress and application of science with its publication.

Other selected journals from SCIRP are listed as below. Submit your manuscript to us via either submit@scirp.org or Online Submission Portal.
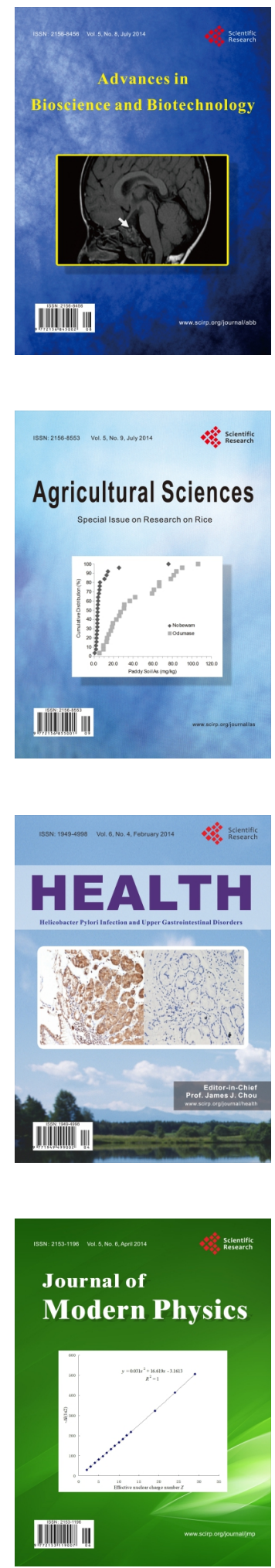
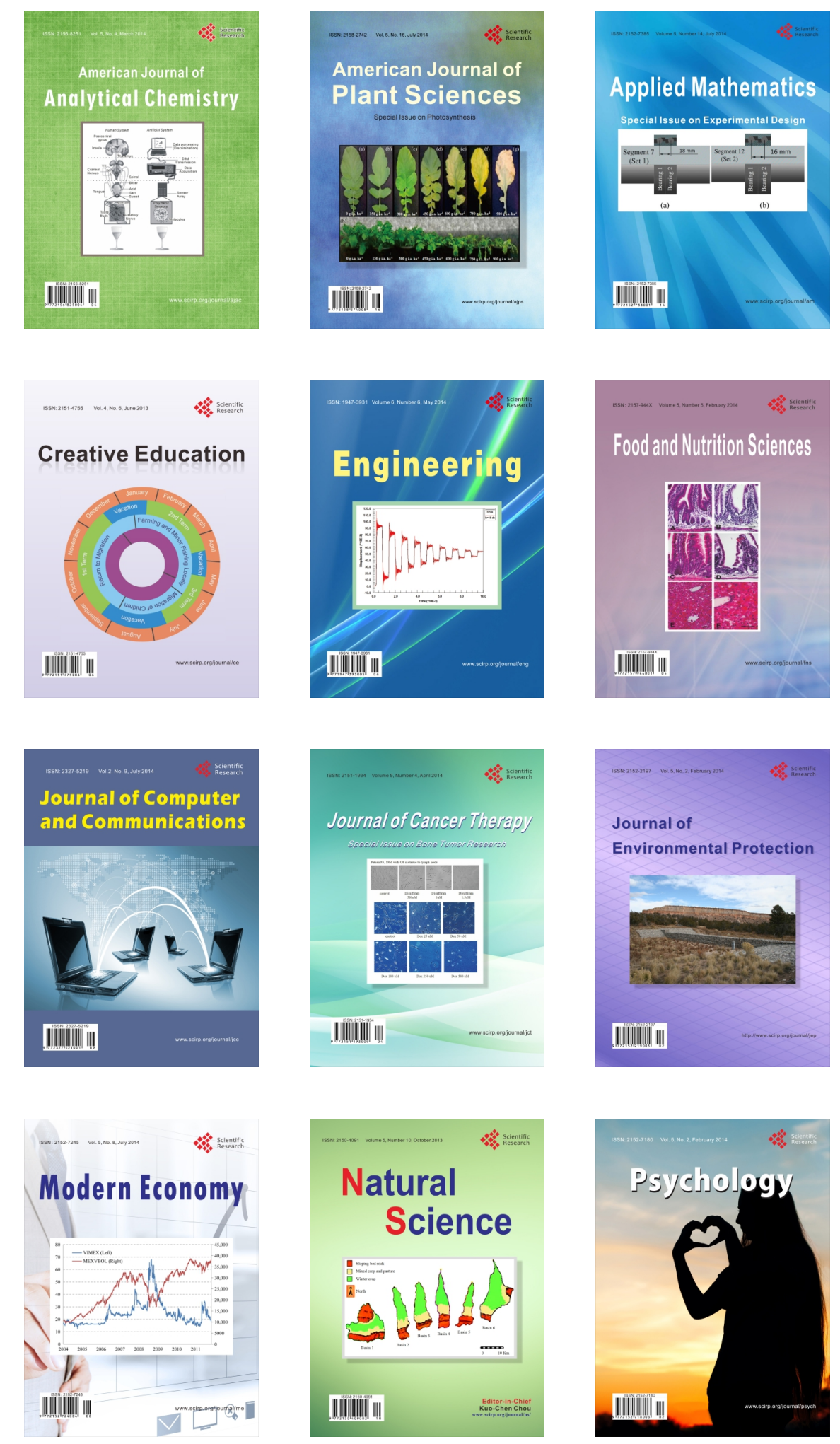